\title{
Metabolic characteristics of autoimmune diabetes mellitus in adults
}

\author{
L. C. Groop ${ }^{1}$, J.Eriksson ${ }^{1}$, A. Ekstrand ${ }^{1}$, A. Franssila-Kallunki ${ }^{1}$, C. Saloranta ${ }^{1}$ and A. Miettinen ${ }^{2}$ \\ ${ }^{1}$ Fourth Department of Medicine, Helsinki University Hospital, and \\ 2 Department of Bacteriology and Immunology, Helsinki University, Helsinki, Finland
}

\begin{abstract}
Summary. It is still a matter of debate whether patients who develop islet-cell antibody positive autoimmune diabetes during adulthood represent slowly evolving Type 1 (insulindependent) diabetes mellitus or a separate subgroup of Type 2 (non-insulin-dependent) diabetes. To address this question, we measured C-peptide response to a test meal, and energy metabolism in the basal state and during a euglycaemic, hyperinsulinaemic clamp in (1) 29 patients with Type 2 diabetes; (2) 10 patients with autoimmune diabetes developing after the age of 40 years; (3) 11 patients with Type 1 diabetes and (4) 15 non-diabetic control subjects. While C-peptide response to a test meal was lacking in Type 1 diabetes and nearly normal in Type 2 diabetes, the C-peptide response in autoimmune diabetes was markedly reduced. $\mathrm{Pa}$ tients with Type 2 diabetes, autoimmune diabetes and Type 1 diabetes showed a $47 \%, 45 \%$ and $42 \%$, respectively, reduction in the rate of non-oxidative glucose metabolism compared with control subjects $(p<0.05-0.01)$. Similarly, patients with Type 2 diabetes $(+52 \%)$, autoimmune diabetes $(+27 \%)$ and Type 1 diabetes $(+33 \%)$ presented with an en-
\end{abstract}

hanced basal rate of hepatic glucose production, which was less suppressed by insulin compared with healthy control subjects $(p<0.01)$. However, patients with autoimmune diabetes derived more energy from oxidation of glucose and proteins and less energy from oxidation of lipids than patients with either Type 1 or Type 2 diabetes $(p<0.05-0.01)$. In conclusion, patients who develop autoimmune diabetes during adulthood share the defects in hepatic glucose production and in non-oxidative glucose metabolism with both Type 1 and Type 2 diabetes. Oxidative energy metabolism in autoimmune diabetes, however, differs from that observed in Type 1 and Type 2 diabetes. Given the metabolic characteristics of these patients, it seems justified to consider autoimmune diabetes in adults as a subgroup of diabetes developing in adult age.

Key words: Type 1 (insulin-dependent) diabetes mellitus, Type 2 (non-insulin-dependent) diabetes, islet cell antibodies, glucose metabolism.
Adult-onset diabetes (onset after the age of 40 years) represents a heterogeneous group including both patients with classic Type 2 (non-insulin-dependent) diabetes mellitus and patients with Type 1 (insulin-dependent) diabetes. While the two extremes are easy to identify, the onset of Type 1 diabetes can in adult patients be insidious and relatively asymptomatic. The patient can therefore, in the beginning, be classified as having Type 2 diabetes and be treated with oral antidiabetic agents. The presence of islet cell antibodies (ICA) in a patient with adult-onset diabetes has been considered a marker for latent autoimmune diabetes or Type 1 diabetes, as these patients usually later require insulin therapy [1-3]. Apart from the presence of ICA and subsequent insulin requirement, it is not known whether autoimmune diabetes in adults (AIDA) share the metabolic characteristics with Type 1 diabetes. This study was undertaken to characterize the defects in insulin secretion, glucose, lipid and protein metabolism in patients with AIDA, and compare them with defects observed in patients with Type 1 and Type 2 diabetes.

\section{Subjects and methods}

Four groups of subjects were studied; (1) 29 patients with Type 2 diabetes, (2) 10 patients with AIDA, (3) 11 patients with Type 1 diabetes, and (4) 15 healthy control subjects (Table 1). Type 2 diabetes was defined as onset of diabetes after the age of 40 years, treatment with oral antidiabetic agents and absence of ICA. AIDA was defined as onset of diabetes after the age of 40 years, and presence of ICA (see below). Nine patients were being treated with insulin (mean insulin dose $30 \pm 4 \mathrm{U} /$ day), while one patient was on sulfonylurea therapy. The AIDA patients had, however, been treated with oral antidiabetic agents for (mean \pm SEM) 
Table 1. Clinical characteristics of the subjects

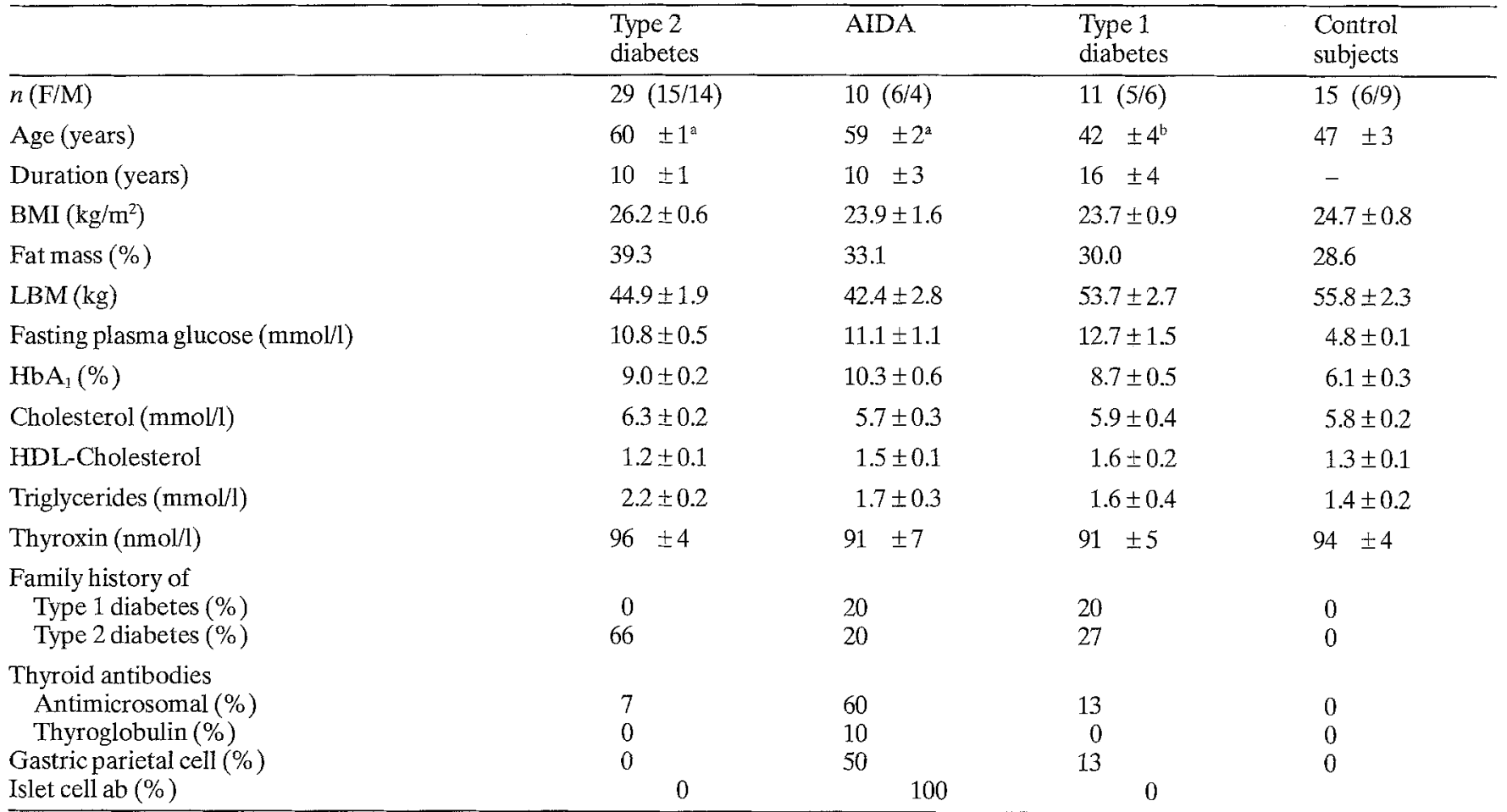

Mean \pm SEM. ${ }^{\mathrm{a}} p<0.01$ vs Type 1 diabetic/control subjects; ${ }^{\mathrm{b}} p<0.01$ vs Type 2 diabetes AIDA. BMI $=$ Body mass index; LBM $=$ Lean body mass

$28 \pm 6$ months before starting insulin therapy. Type 1 diabetes was defined as onset of insulin-dependent diabetes before the age of 40 years. All the Type 1 diabetic patients had presented with ketoacidosis at diagnosis and they required insulin therapy from the time of diagnosis. ICA had not been measured at diagnosis in the Type 1 diabetic patients. Presently, none of them was ICA positive. None of the control subjects had organ-specific antibodies.

\section{Measurements}

All the patients underwent a $3 \mathrm{~h}$ test meal to assess beta-cell function and a $2 \mathrm{~h}$ euglycaemic $(5.5 \mathrm{mmol} / \mathrm{l})$, hyperinsulinaemic $(80 \mu \mathrm{U} / \mathrm{ml})$ insulin clamp (4) in combination with indirect calorimetry and infusion of ${ }^{3}[\mathrm{H}-3]$-glucose to quantitate glucose disposal, hepatic glucose production and net rates of glucose and lipid oxidation. A dietary history was taken in all subjects; all of them consumed normal amounts of carbohydrate (45-50\%), fat $(30-35 \%)$ and protein (15$20 \%$ ) with no difference between the groups. The daily caloric intake was controlled during the 3 days prior to the clamp studies to ensure at least $200 \mathrm{~g}$ of carbohydrates.

Insulin-treated patients were admitted to the hospital on the evening prior to study and a s. c. infusion of $1 \mathrm{U}$ short-acting insulin $/ \mathrm{h}$ (Actrapid Human, Novo Industri, Bagsvaerde, Denmark) was started at 18.00 hours to replace the evening dose of insulin. The s.c. insulin infusion was stopped $180 \mathrm{~min}$ prior to start of the insulin clamp, i.e. at the start of the $\left[{ }^{3} \mathrm{H}-3-\right]$ glucose infusion. Treatment with oral antidiabetic agents was stopped 3 days prior to the studies.

Test meal. The test meal consisted of $60 \mathrm{~g}$ of whole wheat bread, $6 \mathrm{~g}$ margarine, $60 \mathrm{~g}$ cheese, $20 \mathrm{~g}$ marmelade, $200 \mathrm{ml}$ low-fat milk, $125 \mathrm{ml}$ orange juice and a $200 \mathrm{ml}$ cup of coffee ( $68 \mathrm{~g}$ carbohydrate, $600 \mathrm{kcal})$. Blood samples were drawn for plasma glucose and C-peptide determinations at $30 \mathrm{~min}$ intervals during the test meal

Euglycaemic insulin clamp. After obtaining three basal samples for glucose and insulin, a primed-constant infusion of short-acting human insulin (Actrapid Novo) was administered at a rate of
$45 \mathrm{mU} / \mathrm{min} \cdot \mathrm{m}^{2}$ for an average period of $138 \pm 5 \mathrm{~min}$ (includes the additional time required to lower plasma glucose to the euglycaemic level) in the diabetic patients and for $120 \mathrm{~min}$ in the control subjects. The steady state serum free insulin concentrations achieved during the last $60 \mathrm{~min}$ of the clamp in Type 2, autoimmune, and Type 1 diabetes and in control subjects were $85 \pm 3,85 \pm 5,88 \pm 15$ and $81 \pm 3 \mu \mathrm{U} / \mathrm{ml}$, respectively, with a coefficient of variation of $7 \pm 2 \%$. The plasma glucose concentration was determined at 5 min intervals and a variable infusion of $20 \%$ glucose was adjusted to maintain the plasma glucose concentration constant at the euglycaemic level. The coefficient of variation in steady state plasma glucose concentration during the last 60 min of the insulin clamp was $<5 \%$ in all subjects.

At unchanged plasma glucose concentration, the amount of glucose required to maintain euglycaemia equals whole-body disposal of glucose, provided that there is no entry of glucose from the liver. Hepatic glucose production was measured by the isotope dilution technique using $\left[{ }^{3} \mathrm{H}-3\right]$-glucose (Amersham Inc, Amersham, UK) administered as a primed $(25 \mu \mathrm{Ci})$ constant $(0.25 \mu \mathrm{Ci} / \mathrm{min})$ infusion for $180 \mathrm{~min}$ and continued throughout the experiment. Blood samples for determination of insulin and $\left[{ }^{3} \mathrm{H}-3\right]$-glucose specific activity in plasma were obtained in the basal state and at 15 min intervals throughout the $2 \mathrm{~h}$ of the insulin clamp.

Indirect calorimetry was employed in the basal state and during the last $60 \mathrm{~min}$ of the insulin clamp using a computerized open-circuit system (Deltatrac, Datex, Helsinki, Finland) to estimate net rates of carbohydrate and lipid oxidation $[5,6]$. The monitor has a precision of $2.6 \%$ for oxygen consumption and of $1 \%$ for carbon dioxide production.

Lean body mass was determined with the tritiated water dilution technique [7]. Briefly, $40 \mu \mathrm{Ci}$ of tritiated water (Amersham Inc, Amersham, UK) diluted in $0.9 \% \mathrm{NaCl}$ was given as an i.v. injection. Blood samples for the determination of tritiated water specific activity in plasma were drawn before and 80,100 and 120 min after the injection.

Analytical determinations: The plasma glucose concentration was measured by the glucose oxidase method on a Beckman glucose ana- 


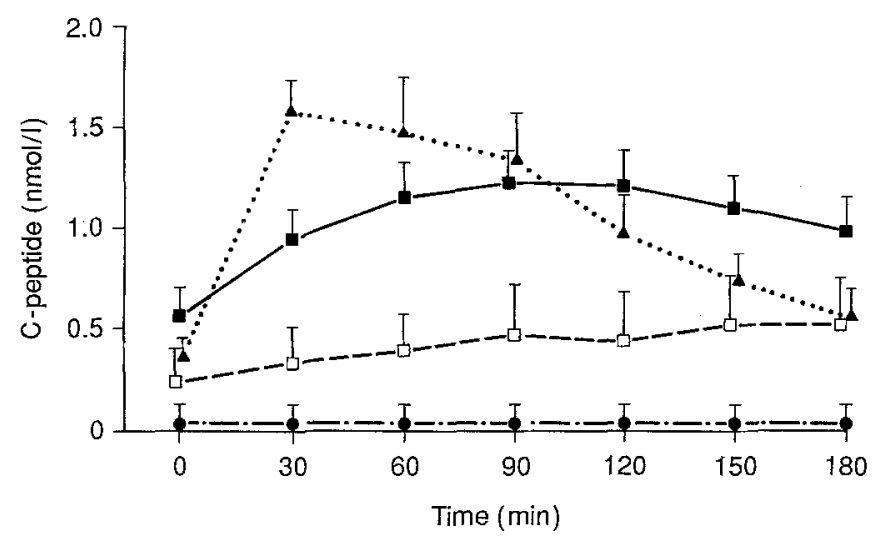

Fig.1. C-peptide response to a test meal in patients with Type 2 diabetes (unbroken line), AIDA (broken line), Type 1 diabetes (broken-dotted line) and in healthy control subjects (dotted line). The area under the concentration curve was significantly lower in Type 1 diabetic patients and AIDA vs healthy control subjects and patients with Type 2 diabetes $(p<0.001)$

lyzer II (Beckman Instruments, Fullerton, Calif,, USA). Glycohaemoglobin concentration in blood was measured by microcolumn chromatography (Isolab, Akron, Ohio, USA). The reference level for the assay was 5-7\%. Serum free insulin concentration was measured as previously described [8]. Serum C-peptide was measured by radioimmunoassay using a specific guinea pig antiserum raised against human C-peptide (Cambridge Medical Diagnostics, Billerica, Mass., USA). Serum thyroxin concentrations were measured by radioimmunoassay; the reference level for euthyroid subjects is $60-160 \mathrm{nmol} / 1$. [ $\left.{ }^{3} \mathrm{H}-3\right]$-glucose specific activity was measured in duplicate on supernatants of $1 \mathrm{~N}$ perchloric acid extracts of plasma samples, after evaporation of radiolabelled water.

Islet cell antibodies were determined in accordance with the recommendation from the International Workshop for the Standardization of ICA $[9,10]$. Indirect immunofluorescence at cryostat sections of blood group 0 pancreas and fluorescein isothiocyanate conjugated anti-human IgG (gamma-chain specific) of the complement-fixing variant (CF-ICA). All sera were tested undiluted and diluted 1:10 with phosphate buffered saline, and positive sera were further tested in serial two-fold dilutions [10]. The sensitivity of the assay was $20 \mathrm{JDF}$ units. All ICA positive subjects had ICA titers of $\geq 40$ JDF units (range 40-600 JDF units), and they were all positive for CF-ICA. Gastric parietal cell antibodies were detected by indirect immunofluorescence technique with cryostat sections of mouse gastric mucosa [3]. Thyroid microsomal (TMab) and thyroglobulin (TGab) antibodies were measured by a passive haemagglutination technique [3]. Titres of $1: 100$ for TMab and of $1: 25$ for TGab were considered positive.

\section{Calculations}

Glucose metabolism. Basal hepatic glucose production was calculated by dividing the $\left[{ }^{3} \mathrm{H}-3-\right]$ glucose infusion rate by the steady state plateau of $\left[{ }^{3} \mathrm{H}-3\right.$ - $]$ glucose specific activity achieved during the last $30 \mathrm{~min}$ of the basal tracer infusion period. After administration of insulin and glucose a non-steadystate condition in glucose specific activity exists, and the rate of glucose appearance was calculated by a two-compartment model [11]. This model, as well as the classic model of Steele [12], is known to produce negative estimates of hepatic glucose production in the presence of high levels of insulin [13, 14]. Negative rates of endogenous (hepatic) glucose production were occasionally observed during the second hour of the insulin clamp, especially in the control subjects. The infusion rate of cold glucose was integrated over $20 \mathrm{~min}$ intervals and subtracted from the total rate of glucose appearance to obtain hepatic glucose produc- tion rate. Total body glucose metabolism was calculated by adding the mean rate of hepatic glucose production (if a positive number) during the last $60 \mathrm{~min}$ of the insulin clamp to the mean glucose infusion rate during the same period. Non-oxidative glucose metabolism was calculated as the difference between total body glucose uptake and glucose oxidation, as determined by indirect calonimetry.

Substrate oxidation. Net glucose and lipid oxidation rates were calculated from indirect calorimetric measurements in the basal state and during the last $60 \mathrm{~min}$ of the insulin clamp. The constants to calculate glucose, lipid and protein oxidation from gas exchange data and urinary nitrogen excretion have been given previously [5]. At a nonprotein respiratory quotient $>1.0$ the equation for the calculation of substrate oxidation remains valid; the remaining negative value for lipid oxidation is in fact equivalent to net fat synthesis [5]. Protein oxidation was calculated from urinary urea nitrogen excretion obtained before and during the insulin clamp.

\section{Statistical analysis}

All data are presented as the mean \pm SEM. Differences between group means were tested with analysis of covariance (ANCOVA) with age as covariate using a BMDP computer program (1 V). Correction for multiple comparisons was performed with Scheffe's test. Correlations were tested with linear regression analysis.

\section{Results}

\section{C-peptide response to meal (Fig. 1)}

The incremental C-peptide response was similar in both the Type 2 diabetic and control subjects ( $3.71 \pm 0.42$ and $3.72 \pm 1.09 \mathrm{nmol} / 2 \cdot 180 \mathrm{~min}$ ), but lacking in the Type 1 diabetic patients $(0.03 \pm 0.02 \mathrm{nmol} / 2 \cdot 180 \mathrm{~min})$. The Cpeptide response in AIDA patients $(0.71 \pm 0.33$ $\mathrm{nmol} / 1 \cdot 180 \mathrm{~min}$ ) was intermediary between Type 1 and Type 2 diabetic/control subjects $(p<0.05$ vs Type 1 diabetic and $p<0.01$ vs Type 2 diabetic/control subjects).

\section{Hepatic glucose production}

The basal rate of hepatic glucose production (HGP) was higher in the Type 2 diabetic than in the control subjects $(4.25 \pm 0.18$ vs $2.80 \pm 0.19 \mathrm{mg} / \mathrm{kg} \mathrm{LBM} . \mathrm{min} ; p<0.01)$, and less suppressed during the insulin clamp $(0.51 \pm 0.09$ vs $-2.56 \pm 0.5 \mathrm{mg} / \mathrm{kg} \mathrm{LBM} \cdot \mathrm{min} ; p<0.01)$. Basal HGP was slightly although not significantly higher in the Type 1 diabetic and AIDA patients $(3.56 \pm 0.20$ and $3.73 \pm 0.50 \mathrm{mg} / \mathrm{kg} \mathrm{LBM} \cdot \mathrm{min}$ ) compared with the control subjects. Suppression of HGP by insulin was impaired in both Type 1 diabetes $(-0.13 \pm 0.16 \mathrm{mg} / \mathrm{kg} \mathrm{LBM} \cdot \mathrm{min}$; $p<0.01)$ and AIDA $(0.10 \pm 0.15 \mathrm{mg} / \mathrm{kg}$ LBM $\cdot \mathrm{min}$; $p<0.01)$ patients compared with control subjects.

\section{Glucose disposal (Fig.2)}

Insulin-stimulated glucose disposal did not significantly differ between Type 2 diabetic, AIDA and Type 1 diabetic patients $(6.13 \pm 0.38,6.78 \pm 0.57$, and $6.03 \pm 0.64 \mathrm{mg} / \mathrm{kg} \mathrm{LBM} \cdot \mathrm{min}$ ), but was lower in both the 

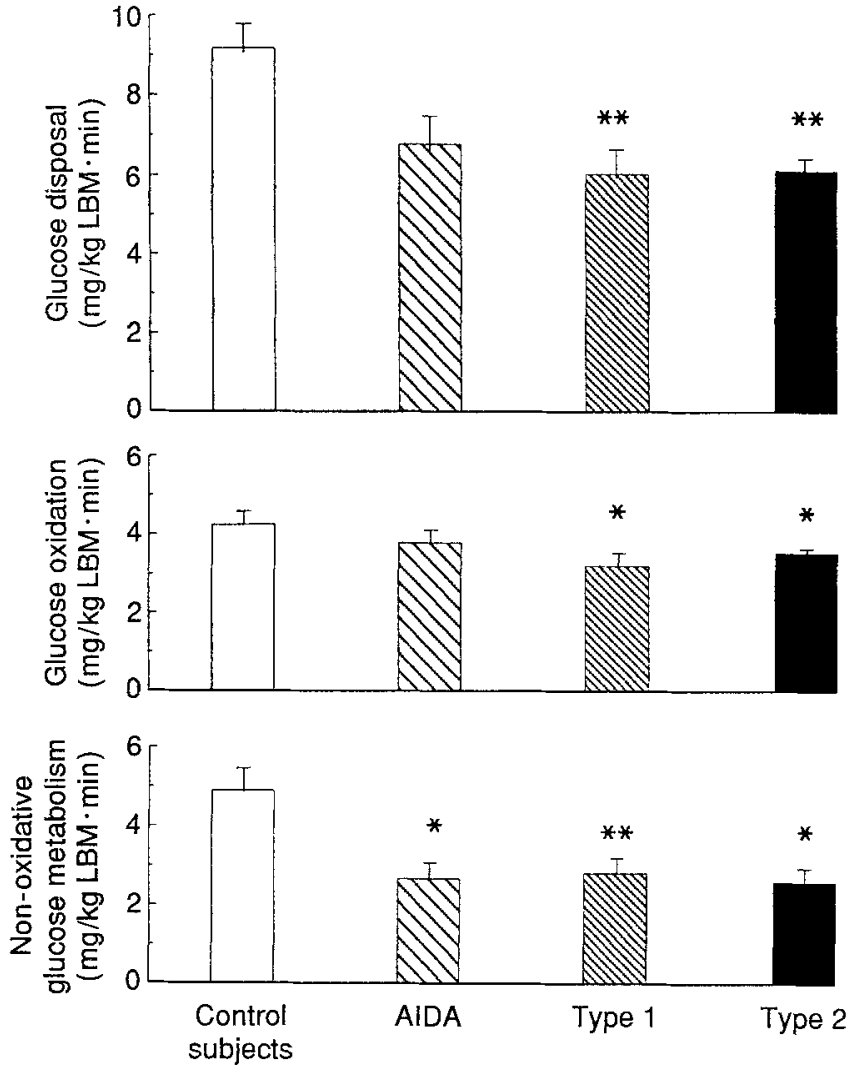

Fig. 2. Rates of total body glucose disposal (top panel), glucose oxidation (mid panel), and non-oxidative glucose metabolism (bottom panel) in Type 2 diabetic, AIDA, Type 1 diabetic and healthy control subjects. * $p<0.05 ; * * * \quad p<0.01$ vs healthy control subjects

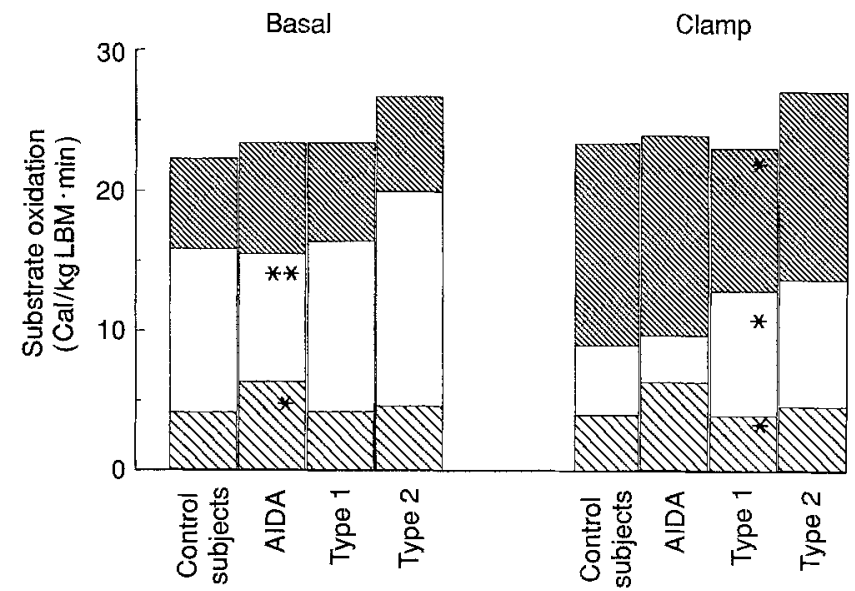

Fig.3. Rates of glucose, lipid and protein oxidation in patients with Type 2 diabetes, AIDA, Type 1 diabetes and in healthy control subjects. * $p<0.05, * * p<0.01$ compared with patients with Type 1 or Type 2 diabetes

Type 2 and Type 1 diabetic patients than in the healthy control subjects $(9.18 \pm 0.69 \mathrm{mg} / \mathrm{kg} \mathrm{LBM} \cdot \mathrm{min} ; p<0.01$.

The impairment in insulin-stimulated glucose disposal in the diabetic patients was almost completely accounted for by impaired non-oxidative glucose disposal ( $p<0.05$ vs control subjects). The rate of glucose oxidation did not differ from the rate observed in the control subjects.
Substrate oxidation and energy production (Fig.3)

In the basal state, AIDA patients were characterized by a higher rate of protein $(1.33 \pm 0.23$ vs $1.08 \pm 0.1$ and $1.1 \pm 0.06 \mathrm{mg} / \mathrm{kg} \cdot \mathrm{LBM} \cdot \mathrm{min} ; p<0.05)$ and a lower rate of lipid $(0.96 \pm 0.06$ vs $1.23 \pm 0.21$ and $1.66 \pm 0.1$ $\mu \mathrm{mol} / \mathrm{kg} \cdot \mathrm{LBM} \cdot \mathrm{min} ; p<0.01$ ) (Fig.3) oxidation compared with patients with Type 1 or Type 2 diabetes. In the insulin-stimulated state, AIDA patients had higher rates of glucose and protein oxidation and lower rate of lipid oxidation than patients with Type 1 or Type 2 diabetes (all $p<0.05$ )

AIDA patients had slightly reduced basal energy expenditure $(0.99 \pm 0.06 \mathrm{Kcal} / \mathrm{min})$ compared with the control subjects $(1.20 \pm 0.06 \mathrm{Kcal} / \mathrm{min} ; \quad p<0.05)$, Type 2 $(1.18 \pm 0.06 \mathrm{Kcal} / \mathrm{min} ; p<0.05)$ and Type $1(1.13 \pm 0.06$ $\mathrm{Kcal} / \mathrm{min} ; p<0.1$ ) diabetic patients. The rate of lipid oxidation correlated with the rate of energy expenditure $(r=0.61 ; p<0.001)$, indicating that the low rate of energy expenditure in AIDA patients partially was explained by the low rate of lipid oxidation.

To test whether the amount of body weight had an influence on the amount of fat oxidized, the rate of lipid oxidation $(\mu \mathrm{mol} / \mathrm{kg} \cdot \mathrm{LBM} \cdot \mathrm{min})$ was correlated with the fat mass $(\mathrm{kg})$. There was no significant correlation between these two variables in the Type 1 diabetic $(r=0.18)$ or Type 2 diabetic $(r=0.04)$ patients and control subjects $(r=0.22)$. On the other hand, in AIDA patients lipid oxidation was inversely related to the fat mass $(r=-0.75$; $p=0.012$ ), indicating that AIDA patients with little body fat had inappropriately high rates of lipid oxidation.

\section{Plasma non-esterified fatty acid (NEFA) concentrations}

The basal plasma NEFA concentrations did not significantly differ between Type 2, Type 1, AIDA and control subjects $(748 \pm 48,621 \pm 52,657 \pm 87$ and $582 \pm 37 \mu \mathrm{mol} / \mathrm{l})$, and were suppressed to the same degree during the insulin clamp $(106 \pm 7,97 \pm 14,125 \pm 21$ and $78 \pm 10 \mu \mathrm{mol} / 1)$.

\section{Discussion}

Despite marked differences in the C-peptide response to a test meal, the Type 2, AIDA and Type 1 diabetic groups showed a similar impairment in the rate of non-oxidative glucose metabolism. The data on the effect of insulin on hepatic glucose production should be interpreted with caution. Significant negative values for hepatic glucose production were observed in the control subjects, who also showed the highest rate of glucose disposal. This has been explained by the fact that the tracer technique under such circumstances underestimates the rate of glucose disappearance, and that this error is then reflected on the estimates of hepatic glucose production $[13,14]$. On the other hand, glucose disposal was similar in all three diabetic groups suggesting that the estimates of hepatic glucose production during the insulin clamp should be comparable in the diabetic groups. 
These data also suggest, that several pathogenic mechanisms can be involved in the development of reduced storage of glucose as glycogen in muscle tissue. Evidence has accumulated that the defect in non-oxidative glucose metabolism seen in Type 2 diabetes is inherited $[6,15]$, and observed at a stage when insulin secretion is normal. Insulin deficiency or the ensuing hyperglycaemia, as observed in patients with Type 1 diabetes and AIDA, can also lead to disturbed muscle glucose metabolism [16-19]. The findings that correction of insulin deficiency and hyperglycaemia can reverse the disturbances in glucose utilization in such patients support the concept of secondary defects $[17,19,20]$.

Although non-oxidative glucose metabolism was similar in the three diabetic groups, they displayed marked differences with respect to substrate oxidation. In the basal state, AIDA patients derived less energy from oxidation of fat $(39 \%)$ and more energy from oxidation of proteins $(27 \%)$ than patients with Type $1(52 \%$ and $18 \%)$ or Type $2(58 \%$ and $17 \%)$ diabetes. In the insulin-stimulated state, the contribution of glucose oxidation to energy production was similar in AIDA patients and control subjects $(60 \%$ and $61 \%)$ but two-fold higher than in patients with Type $1(30 \%)$ or Type $2(33 \%)$ diabetes. Despite the low basal rate of lipid oxidation, the fractional rate of lipid oxidation (i.e. lipid oxidation/fat mass) was high in the AIDA patients.

The high rate of protein oxidation in AIDA patients deserves some comments. Whereas glucose and lipid oxidation rates are estimated from oxygen consumption and carbon dioxide production (indirect calorimetry), protein oxidation is estimated from urinary nitrogen excretion. This is based upon the assumption that urinary nitrogen excretion represents $>90 \%$ of nitrogen removal from protein oxidation. It is clear that this is subject to other sources of errors than the calorimetric measurements and that estimates of protein oxidation are more crude than estimates of glucose or lipid oxidation. A diet rich in protein could provide an explanation for the high rate of protein oxidation in the AIDA patients. It is interesting to note, that a protein-enriched diet in rats can induce both hepatic and peripheral insulin resistance [21]. This explanation is, however, unlikely, since according to the dietary history, the AIDA patients consumed the same amounts of protein as the other groups. Another explanation could be that the AIDA patients were in a more catabolic state than the other patients. Whether this is unique to the metabolic situation of AIDA or a consequence of associated autoimmune disease (thyroid, gastric?) is unknown. Thyroid function as measured by serum thyroxin concentrations was normal in all subjects.

At variance with the change in net lipid oxidation measured by indirect calorimetry, plasma NEFA concentrations did not differ between patients with AIDA and patients with Type 1 or Type 2 diabetes. Studies using ${ }^{14} \mathrm{C}$ palmitate to trace NEFA oxidation simultaneously with indirect calorimetry have shown, that oxidation of (plasma) NEFA accounts for approximately $2 / 3$ of net lipid oxidation measured by indirect calorimetry $[22,23]$. Since ${ }^{14} \mathrm{C}$-palmitate traces only the circulating NEFA pool, whereas indirect calorimetry measures total (intracellular plus extracellular) lipid oxidation, the significant difference between net lipid oxidation and NEFA oxidation indicates direct oxidation of intracellular lipids. Although we did not measure plasma NEFA oxidation in the present study, we have previously shown, that the plasma NEFA concentration is a major determinant of its own oxidation rate [23]. We can therefore deduce from the plasma NEFA concentrations that the rate of lipolysis and plasma NEFA oxidation were similar in the three diabetic groups. The difference in sensitivity of net lipid oxidation to insulin between AIDA and Type 2 diabetes must therefore be due to differences in sensitivity of intracellular lipid oxidation. The localisation (intramuscular?) and source of this intracellular lipid oxidation is unknown.

The question remains whether AIDA represents a subtype of diabetes or is simply the consequence of late manifestation of Type 1 diabetes. Patients with AIDA shared hepatic glucose overproduction and impaired nonoxidative glucose metabolism with both Type 1 and Type 2 diabetes. Energy metabolism in AIDA, however, differed from that in Type 1 and Type 2 diabetes with higher rates of glucose and protein and lower rates of lipid oxidation. The data thus indicate that the metabolic characteristics of autoimmune diabetes developing in adult age differ from those observed in Type 1 and Type 2 diabetes. This does not mean per se that the pathogenic mechanisms in AIDA also differ from those in Type 1 diabetes.

Acknowledgements. This study was supported by grants from the Sigrid Juselius Foundation, Finska Läkaresällskapet und the Perklén Foundation. The expert technical help by Mr. E. Laurila, Ms. S.Heikkinen, A.-C.Blomquist and A.Putkonen is gratefully acknowledged.

\section{References}

1. Irvine WJ, Gray RS, McCallum CJ, Duncan LJP (1977) Clinical and pathogenetic significance of pancreatic islet antibodies in diabetes treated with oral hypoglycemic agents. Lancet I: 1025-1027

2. Groop LC, Bottazzo GF, Doniach D (1986) Islet cell antibodies identify latent type 1 diabetes in patients aged $35-75$ years at diagnosis. Diabetes 35: 237-241

3. Groop LC, Miettinen A, Groop P-H, Meri S, Koskimies S, Bottazzo GF (1988) Organ-specific autoimmunity and HLA-DR antigens as markers for $\beta$-cell destruction in patients with type II diabetes. Diabetes 37: 99-103

4. DeFronzo RA, Tobin JD, Andres R (1979) Glucose clamp technique: a method for quantifying insulin secretion and resistance. Am J Physiol 237: E214-E223

5. Ferrannini $E$ (1988) The theoretical basis for indirect calorimetry: a review. Metabolism 37: 287-301

6. Eriksson J, Franssila-Kallunki A, Ekstrand A, Saloranta C, Widén E, Schalin C, Groop L (1989) Early metabolic defects in individuals at increased risk of developing non-insulin dependent diabetes mellitus. N Engl J Med 321:337-343

7. Coleman TG, Manning RD Jr, Norman RA Jr, Guyton AC (1972) Dynamics of water-isotope distribution. Am J Physiol 223: $1371-1375$

8. Hanning I, Home PD, Alberti KGMM (1985) Measurement of free insulin concentrations: the influence of the timing of extraction of insulin antibodies. Diabetologia 28: 831-835 
9. Bottazzo GF, Gleichmann H (1986) Immunology and Diabetes Workshops: report of the first international workshop on the standardization of cytoplasmic islet cell antibodies. Diabetologia 29: $125-126$

10. Miettinen A, Holthöfer H, Kontiainen S, Miettinen M, Andersson LC (1989) Antibodies against gastrointestinal tumours in IDDM. Diabetes 38: 667-669

11. Radziuk J, Norwich KH, Vranic M (1974) Measurements and validation of non-steady state turnover rates with application to the insulin and glucose systems. Fed Proc 33: 1855-1864

12. Steele R (1959) Influence of glucose loading and of injected insulin on hepatic glucose output. Ann NY Acad Sci 82: 420-430

13. Cobelli C, Mari A, Ferrannini E (1987) Non-steady state: error analysis of Steele's model and development for glucose kinetics. Am J Physiol 252: E679-E689

14. Yki-Järvinen $\mathrm{H}$, Consoli A, Nurjhan N, Young AA, Gerich JE (1989) Mechanism for underestimation of isotopically determined glucose disposal. Diabetes 38: 744-751

15. Lillioja S, Mott DM, Howard BV, Bennett PH, Yki-Järvinen H, Freymond D, Nyomba BL, Zurlo F, Swinburn B, Bogardus C (1988) Impaired glucose tolerance as a disorder of insulin action Longitudinal and cross-sectional studies in Pima Indians. N Engl J Med 318: 1217-1225

16. Reaven GM, Sageman WS, Swenson RS (1977) Development of insulin resistance in normal dogs following alloxan-induced insulin deficiency. Diabetologia 13: 459-462

17. Caruso $G$, Proietto J, Calenti A, Alford F (1983) Insulin resistance in alloxan-diabetic dogs: evidence for reversal following insulin therapy. Diabetologia 25:273-279

18. Unger RH, Grundy S (1985) Hyperglycemia as an inducer as well as a consequence of impaired islet function and insulin resis- tance: implications of the management of diabetes. Diabetologia 28: 119-121

19. Rossetti L, Smith D, Shulman GI, Papachristou D, DeFronzo RA (1987) Correction of hyperglycemia with phlorizin normalizes tissue sensitivity to insulin in diabetic rats. J Clin Invest 79: $1510-1515$

20. Garvey WT, Griffin J, Hamman RF, Kolterman OG (1985) The effect of insulin treatment on insulin secretion and insulin action in type II diabetes mellitus. Diabetes 34: 222-234

21. Rossetti L, Rothman DL, DeFronzo RA, Shulman GI (1989) Effect of dietary protein on in vivo insulin action and liver glycogen repletion. Am J Physiol 20: E212-E219

22. Dagenais GT, Tancredi RG, Zierler KL (1976) Free fatty acid oxidation by forearm muscle at rest, and evidence for an intramuscular lipid pool in the human forearm. J Clin Invest 58: 421-431

23. Groop LC, Bonadonna RC, Del Prato S, Ratheiser K, Zyck K, Ferrannini E, DeFronzo RA (1989) Glucose and free fatty acid metabolism in non-insulin dependent diabetes mellitus. Evidence for multiple sites of insulin resistance. J Clin Invest 84 : 205-213

Received: 22 November 1989

and in revised form: 25 July 1990

C. Groop, M.D.

Fourth Department of Medicine

Helsinki University Hospital

Unioninkatu 38

SF-00170 Helsinki

Finland 